\title{
TRAINING AND ADVISORY SERVICES: PREFERENCES OF LOCAL SERVICE PROVIDERS AND RECEIVERS
}

\section{ELŻBIETA SKĄPSKA}

Bialystok University of Technology, POLAND

e-mail: e.skapska@pb.edu.pl

RECEIVED
ACCEPTED
JEL
CLASSIFICATION

KEYWORDS

ABSTRACT

\author{
20 April 2018 \\ 12 July 2018 \\ D11, D33, D70
}

services, preferences, consumers, enterprises, local market

The fact there is good accessibility to modern service-product offers has imposed greater requirements on managers who make market decisions concerning the survival and development of local enterprises. Observation of current consumer behavior and a quick response as for meeting clients' expectations and needs with a quality product have become a necessity. The article uses entrepreneurs from Białystok as examples of training providers and their service receivers. The scientific aims, that have been reached by the Delphi method, included: firstly, establishing the degree of preference accordance of local enterprise service providers and their receivers; secondly, indicating the list of recommendations with reference to actions that could provide entrepreneurs with a better adjustment of their offers, thus a better answer to their customers' needs. As a result, the transformed information is used in realization of tasks and acquisition of competitive advantage while making a profit and ascending to a higher level of business entity development.

\section{Introduction}

Large business managers are often concerned with training of their personnel and reach for advisory services in the field of professional services such as legal counseling, accounting or medical counseling. It does not only regard knowledge-oriented enterprises, i.e. running mainly service business. The range of training subjects is very broad and, in terms of development, it allows a company to successfully use the knowledge. The article takes into 
account market conditions (a local perspective) for the training service development and presents preferences of service providers and service receivers as for the training service. Possibilities of additional training produce beneficial solutions for receivers of the service, who then are able to balance and adjust their preferences as for work and life of their workers, and a company itself, as it can obtain greater innovative potential which is necessary to attract and maintain employees (Malhotra, Smets, Morris, 2016). In services, unlike in material-good business, there is a high level of proximity between the front personnel and consumers. Due to this feature, social factors such as demography, social-economic status, education, preferences of consumers have an enormous influence on effective relations (Subranomy, 2017). Managing and organizing relations means creating, developing, maintaining and optimizing a long-term business strategy. Client's satisfaction is necessary in order to facilitate repeated purchases and lower the costs of acquisition (Njuguma, Mirugi, 2017). The success requires, among the other, proper selection of the offer. For instance, business receivers are mostly engaged in subjects such as general business, executive-level development, education, engineering, project management, technology, healthcare. What fields do those receivers come from? Major clients or industries served in 2015 include: biotech construction, defense, education, finance, local government authorities, healthcare, manufacturing, technology, telecommunication (Education, 2017).

\section{Local market of training-advisory services from the general perspective}

In Podlaskie province, most training companies operate in major cities of the region: in Białystok, Łomża and Suwałki. In Białystok, there are 4 times more of them than in other cities. According to the training institution register (RIS in Polish), in the period of 1.01.2016-31.12.2016, the numbers of those institutions for respective cities were: $198,35,46$. Public institutions constituted $6.5 \%$ and nonpublic institutions $3.5 \%$. For the most researched companies the local market is not sufficient as for the access to the preferred trainings or their availability, mainly specialized trainings, which is also confirmed by the research results of the article. In managers' opinions, employees do not search for the stabilization that is connected with a single job position. They value the prospect of changing a job more than a job with a progressive post. Over-than-average profitability of introducing new services is the main reason for managers to introduce services of added value (Skapska, 2017). According to the province employment agency in Białystok, the most frequently designated subjects of trainings cover: transportation, personality and job career development, information technology and use of computers, healthcare, technology and trading technical goods, sales, marketing, public relations, real estate trade.

\section{Training-advisory services. Research methodology}

The main research into training-advisory services was performed in October and November of 2017 and it covered 20 enterprises that had been chosen from among the group of service providers and receivers. The key criteria of selection of companies was their popularity and prestige on the local market - Białystok and its vicinity. The study was carried out by a means of an in-depth direct interview with decision makers which was supported and delivered by electronic means. In case of the training companies, training managers were interviewed, and in case of companies that use the training, the interview included the staff like presidents and human resource managers.

The service providers group included 10 well-known and recognized training companies:

- T-Matic Grupa Computer Plus (IT services),

- Centrum Kształcenia Ustawicznego CKU (in-service training), 
- Rada FSNT NOT (construction expertise) in Białystok,

- Ośrodek Kształcenia Zawodowego ZDZ (in-service training) in Białystok,

- EkoExpert Doradztwo Ekologiczne i Gospodarcze Sp. Z o. o. (Ecological-economic advisory),

- Stowarzyszenie Księgowych (an association of accountants) in Poland - Local branch in Białystok,

- other entities providing training in the scope of accounting, tax and economic law, soft skill trainers who teach for the internal purposes of a company, trainings in OHS and energetics.

The group of service receivers constituted 10 selected entrepreneurs who delegate their personnel for training. There were many recognized innovative companies of Podlasie region such as:

- PLUM (intelligent technology solutions) in Ignatki,

- from production-trade branch - PRONAR Sp. z 0.0. (producer of, among others, farming machines) in Narew

- other businesses from IT and RTV trades, companies of energy sector - liquid gas distributors, metal hardware manufacturers, trade market companies or producers from the industrial automation field.

\section{Preferences with regard to service offer - research results}

Offer priorities has been changing depending on the current internal demands of companies and according to the constantly changing market conditions. The list of preferences that emerged from training service companies included: knowledge, quality, utility, a price, capital, training for companies as well as individual training (Figure 1). In the first place, service providers mentioned quality that was expressed by a proper selection of trainers and a price. The following items concerned knowledge, training utility, company-directed trainings. Less attention was paid to training for an individual receiver and to modern real capital.

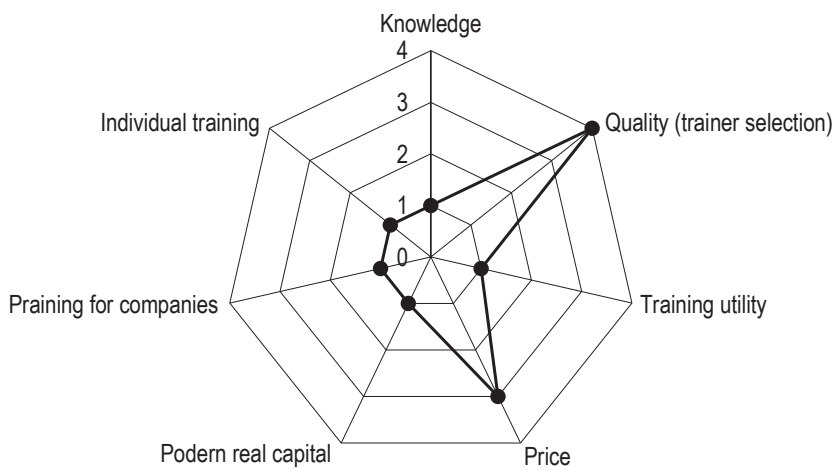

Figure 1. Preferences of service providers

Source: own elaboration based on the research.

The factors or criteria mentioned and valued by service receivers covered the following groups of categories: contact with employers, a price, obtained occupational powers, a training subject, a practical application of the knowledge, opinions, a competent trainer, e-learning, high functionality and utility of trainings, timeliness, a workshop form of trainings, needs. 
The service receivers' preferences differ from the preferences of the providers. The providers favor the quality whereas the receivers concentrate on the price as their first choice. A reliable and competent trainer as a service quality creator in the ranking of service receivers takes a lower place than the price. Thus, the common features that link both preferences of the providers and the receivers are a price and utility.

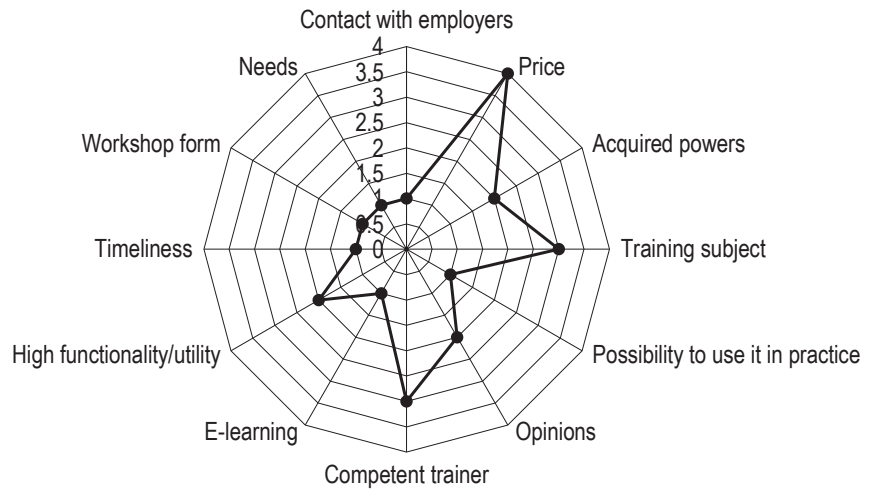

Figulp 2. Preferences of service receivers as for training service features

Source: own elaboration based on the research.

The training receivers indicated the following items as priority factors: a price, a competent trainer, a training subject. A significant kind of training for clients of training companies (Figure 3 ) is a group training.

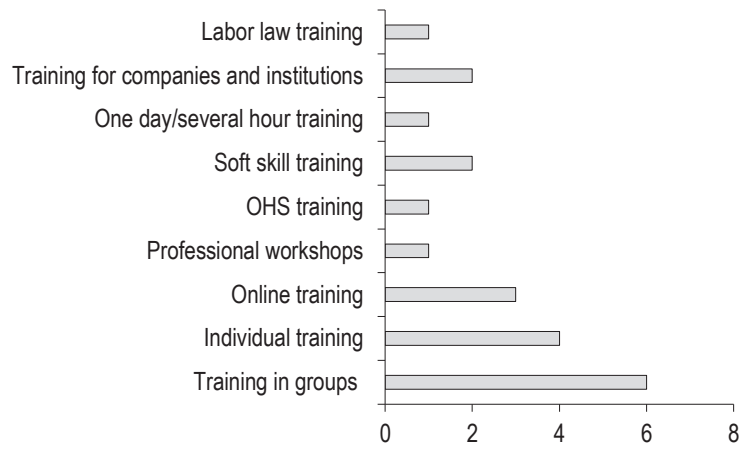

Figure 3. Preferences as for kinds and forms of training (the more economic the more wanted)

Source: own elaboration based on the research.

A convenient and popular form of training is an online training which, most of all, lets one save time. The trainees are also willing to use the training that concerns the acquisition of soft skills (dealing with stress, time management, interpersonal communication). 


\section{Delegating employees for training - motives}

Depending on most representatives of the researched companies, sending workers for trainings are a means of motivating that allows to achieve better efficiency at work. The participation in trainings affects the increase of commitment as employees understand it as an investment in their development. After obtaining new knowledge their new task is to pass it to their fellow colleagues. All the acquired knowledge may contribute to the improvement of the sales quality which translates into sales results and consequently into the salary amount. Improving vocational qualifications, by means of trainings, conditions functioning and development of company's activity in a competitive environment.

Enterprise usually use 12 to 17 trainings annually. Obviously there are companies, like Plum in Ignatki, whose number of trainings exceeds 20 per year. There are a few companies whose numbers go from 1 to 5 and 6 to 11 .

Making a decision on purchasing the training, for the respondents, means being influenced by the following factors:

- training subject,

- possibility to use acquired knowledge in practice,

- high functionality of service and its potential to satisfy utility needs,

- timeliness,

- training substantive level,

- workshop form,

- trainers' qualifications and affordable price,

- other/previous trainees' opinions on the training company.

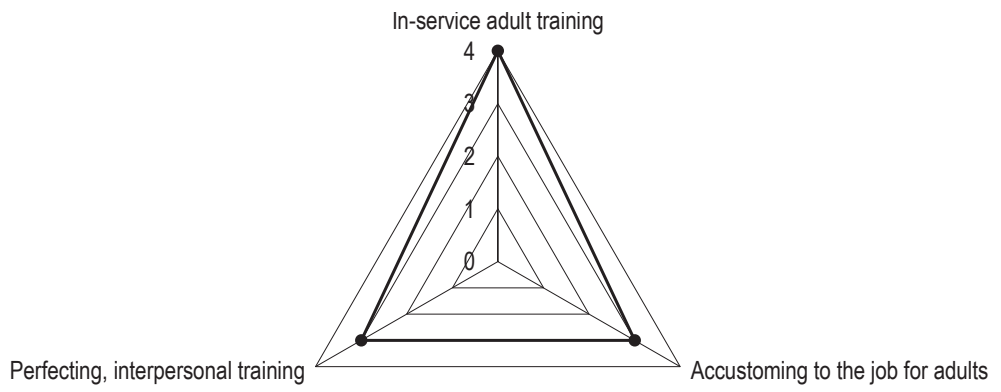

Figure 4. Receivers' preferences for types of training

Source: own elaboration based on the research.

Some trainings concerned soft skill acquisition with regard to assertiveness, creativity, coping with stress or trainings that complement knowledge. Training service receivers approve of the workshops that are run, most of all, by people with professional knowledge. It does not matter whether they are young or old as long as they are experienced. It is also important that trainers are communicative, however, it is a secondary trait (Figure 5). 


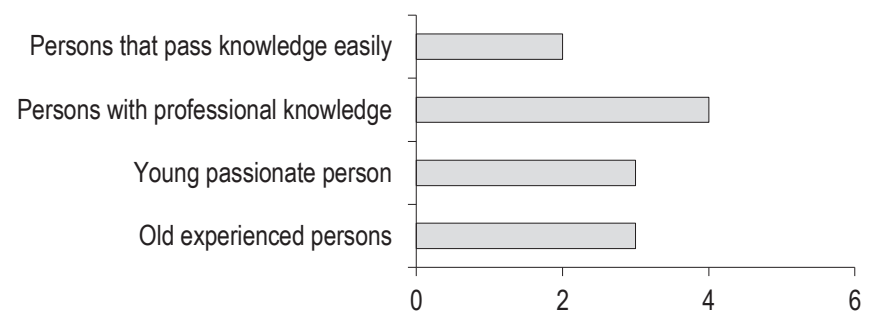

Figure 5. Receivers' preferences as for traits of trainers

Source: own elaboration based on the research.

According to receivers, the local market (Bialystok) is not so developed yet. The offers are, in most cases, produced in way, with regard to their number and training quality, that they only suffice for the local market. However, some receivers are forced to search for offers on other markets like a regional, national, or an international market. It results from the built structure of a company and the headquarters of a training department which often has its seat in the capital city. Thus, all training activity of such company is performed nation-wide. Other reason is the fact that the local market, for instance the IT market, is too small, and competition of the market is very varied. Another reason of looking for different markets is the desire to participate in specialized trainings. Using mainly local services is limited and disadvantaged by a small distance between Bialystok and Warsaw where, obviously, there is a broader access to specialized trainings.

Furthermore, after decreasing the European union endowment, the training market has considerably shrunk as for its offer of subjects. There are companies that have their own training departments and run trainings in its particular departments of a given territory with regard to workers being client advisors (subjects like the range of sales techniques) and managers (subjects cover soft skill competence such as communication, building a team, problem solving, planning, creating coaching culture). Companies also often prefer trainings that are carried out by external companies, as for the product knowledge. They take place, for instance, monthly and are dedicated to store employees who are taught about the sold products.

Companies, that delegate their employees for trainings, suggest that the training companies perform the following tasks in order to satisfy their clients' needs better:

- introduction of new ways of recruiting and new working conditions,

- presenting the newest knowledge at the world level,

- using the leading international companies' experience.

Many training service receivers notice that expenditure on trainings is not the cost or burden. It is rather an investment and an improvement on company's potential. This expenditure is a conscious choice and a proof of leading a proper training policy within the national network and it is in accordance with the business character.

\section{Training effectiveness in view of service providers and peceivers}

Establishing preferences is tightly connected with the vision of reaching effectiveness (Figure 6) by means of a proper service offer. There are sources of information on trainings such as: development databases, websites of training companies, online invitations, participants' opinions, trade contacts. An interesting fact that arises from the research is that companies from both sides record the equality of training effects and expenditure - few 
companies reach the advantage of effects over the expenditure which means that the level of cost-effectiveness of business is not satisfactory (below expectations). From the point of view of trainees it may be seen as a norm, i.e. in accordance with expectations as the input, especially financial one, is adequate to the outcome.

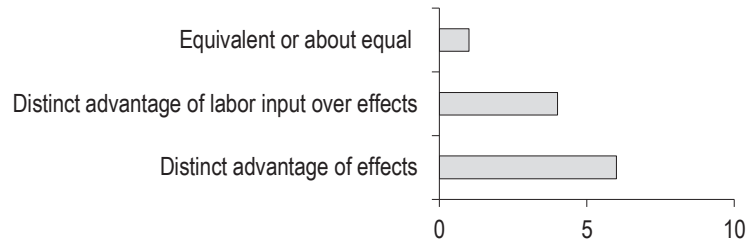

Figure 6 . Effectiveness of trainings according to representatives of companies that delegate workers for training Source: own elaboration based on the performed research.

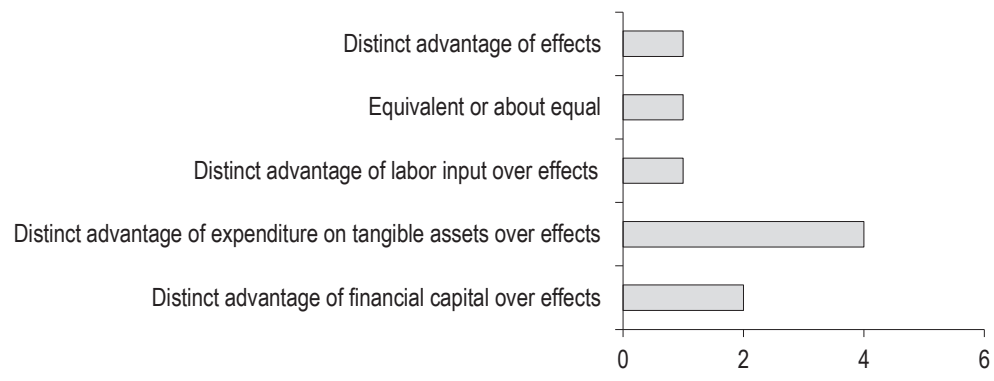

Figure 7. Training effectiveness according to managers of training companies

Source: own elaboration based on the performed research.

Observing the outcome of the research, as for the effectiveness from the standpoint of the training companies, few experts have indicated the distinct advantage of expenditure over the effects, i.e. labor, expenditure on tangible assets and financial capital.

\section{Conclusions}

The outcome of the performed study may be formed as a list of recommendations and advice for training companies. These recommendations are as follows:

- increase the number of specialized trainings for residents of the region,

- allocate a larger budget for the purposes of advisory-training offers for companies and institutions,

- raise the level of competitiveness and innovativeness of service providers through presenting the newest knowledge at the highest level,

- care for coaching culture as the preferences of training service receivers still concentrate around the group training and training workshops which should be noticed by training providers. 


\section{References}

Education, Book of Lists (2017). San Diego Business Journal, January 1 (Table, p. 93).

Malhotra, N., Smets, M., Morris, T. (2016). Career Pathing and innovation in professional service firms. Management Perspectives, 4 (30).

Njuguma, R.K., Mirugi, S. (2017). The effectiveness of relationship management and service quality on service delivery. International Journal of Sales, Retailing\&marketing, 2 (6).

Skapska, E. (2017). Innovative entrepreneurship evaluation in opinion of service company managers in Podlaskie Province. Institute of Economic Research Working Papers, 115.

Subranomy, M. (2017). Service organizations and their communities: perspectives and new directions and new directions for management research. Academy of management Perspectives, 1 (31).

Wojewódzki Urząd Pracy w Białymstoku (2016). Analiza działalności i oferty szkoleniowej instytucji szkoleniowych województwa podlaskiego posiadających wpis do RIS w 2016 roku (attachment). Retrieved from: http://wupbialystok.praca.gov.pl (12.08.2017).

Cite this apticle as: Skapska, E. (2018). Training and advisory services: Preferences of local service providers and receivers. European Journal of Service Management, 3 (27/1), 269-276. DOI: 10.18276/ejsm.2018.27/1-34. 